\title{
Seasonal variations in the incidence of auroral radio absorption events at very high latitude, and the influence of the magnetotail
}

\author{
J. K. Hargreaves \\ Dept. of Communication Systems, University of Lancaster, Bailrigg, Lancaster LA1 4WA, UK \\ Received: 27 September 2006 - Revised: 4 January 2007 - Accepted: 27 February 2007 - Published: 29 March 2007
}

\begin{abstract}
A statistical analysis has been made of the incidence of auroral radio absorption events at South Pole, and of its dependence on basic geophysical parameters such as season, time of day, and magnetic activity level. It is found that at low and moderate levels of activity the incidence of events in the winter season is at least twice that in the summer. However, at high activity no events at all occurred during the local summer night, which appears to be explicable as the effect of the magnetotail and the consequent distortion of the magnetosphere when the southern polar region is tilted strongly towards the Sun. Previous results from even higher latitudes show the effect in an even more exaggerated form, in that both the day and night periods of absorption activity exhibit strong seasonal variations.
\end{abstract}

Keywords. Ionosphere (Auroral ionosphere; Particle precipitation) - Magnetospheric physics (Magnetotail)

\section{Introduction}

The incidence of auroral radio absorption, normally observed with riometers, is essentially zonal with an occurrence maximum at or near $67^{\circ}$ geomagnetic latitude $(\mathrm{L} \sim 7)$. The width of the absorption zone, assuming a Gaussian form of distribution, is about $\pm 7^{\circ}$ on average. The magnitude and the rate of occurrence of absorption events at these latitudes vary strongly with the level of disturbance as indicated by indices such as $K_{p}$ and $A_{p}$, and the latitude of the maximum also changes with the intensity of the disturbance, moving down in latitude if the activity becomes more intense. The occurrence statistics of auroral absorption were thoroughly investigated in the earlier years of riometer studies (Hargreaves, 1969a) with the emphasis placed on the activity at and around the latitudes of maximum occurrence, but also

Correspondence to: J. K. Hargreaves

(j.hargreaves@lancaster.ac.uk) including the magnetic latitude of South Pole (Hargreaves et al., 1964; Hargreaves and Cowley, 1967a). At the higher magnetic latitudes statistical investigations tend to be more difficult because the absorption events are smaller and less frequent. However, studies which have been made (e.g. Gillmor and Hargreaves, 1963; Satterblom et al., 1967) show some interesting features which are not evident at the lower latitudes.

Conjugate-point observations made between the Canadian Arctic and the Antarctic in the 1960s (Hargreaves and Chivers, 1965; Hargreaves and Cowley, 1967b) revealed a seasonal variation in the relative intensity of conjugate absorption events, their magnitude tending to be greater in the winter hemisphere. This effect was strong at the magnetic latitude of South Pole (L 14) and less strong, though still clearly present, at the latitude of Byrd Station $(\mathrm{L} \sim 7)$. No such effect was apparent between Eights Station $(L=4)$ and its conjugate. The effect could be due (i) to a seasonal difference in electron precipitation and/or in the atmospheric response to the precipitation, (ii) to a relative shift in the position of the occurrence zone, or to a combination of these factors. A subsequent investigation using spaced riometers at L 7 (Hargreaves, 1969b) suggested that both kinds of cause played some part at stations near the latitude of peak occurrence. The situation regarding higher latitudes has never been resolved, however.

The purpose of the present study is to investigate in greater detail the incidence of auroral absorption at South Pole and higher magnetic latitudes, with particular regard to the influences of season and activity level.

\section{Data}

Riometer data from South Pole recorded over the three-year period 1990-1992 were inspected for the occurrence of absorption events peaking at or above a selected magnitude.

Published by Copernicus GmbH on behalf of the European Geosciences Union. 


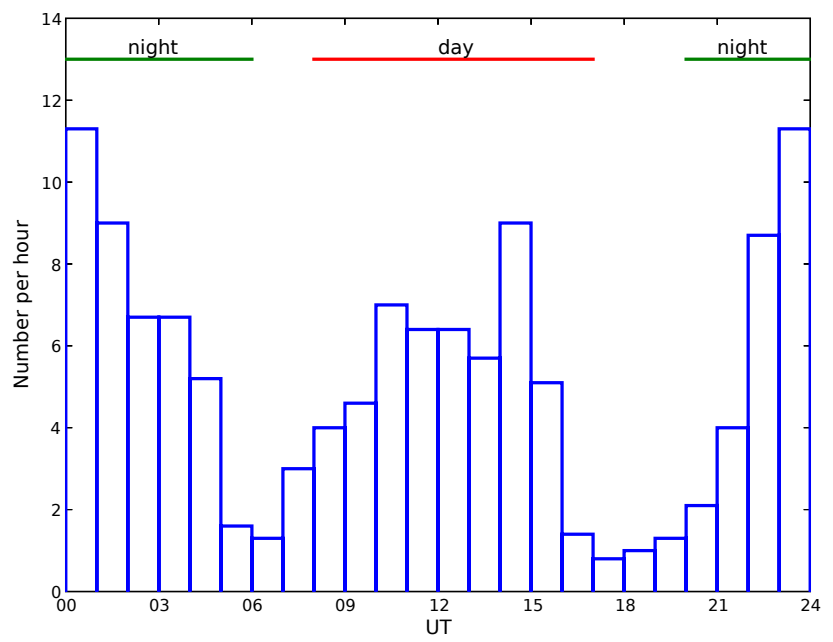

Fig. 1. Incidence of auroral absorption events exceeding the threshold value at South Pole according to the time of day. Magnetic midnight and noon are at about 04:00 and 16:00 UT, respectively. The ordinate gives the total number of days in an average year that an event occurred in an hour.

The riometers operated at $38.2 \mathrm{MHz}$ in 1990 and 1991, and at $51.4 \mathrm{MHz}$ in 1992 . The threshold was set at $0.3 \mathrm{~dB}$ for 1992 , and at $0.54 \mathrm{~dB}$ in $1990-1991$, both of these limits being equivalent to $0.88 \mathrm{~dB}$ at $30 \mathrm{MHz}$. The basic method was simply to note the hour and month when events exceeding the threshold occurred, and the magnetic activity index $A_{p}$ for that day. Days showing polar-cap absorption and any with poor quality data, for whatever reason, were disregarded. In studies of the monthly incidence, the count was multiplied by $30 / \mathrm{N}$, where $\mathrm{N}$ is the number of days inspected, thereby correcting the incidence to a standard month of 30 days.

\section{Results}

\subsection{Diurnal variation}

Previous work has shown that at the latitude of South Pole the events occur principally within separate night and day periods, the incidence being low for $2-3 \mathrm{~h}$ in the early morning and the early evening (Hargreaves et al., 1964). The same features are seen in the present results (Fig. 1), in which the ordinate is the number of events within the hour over one year. At South Pole magnetic time is about $4 \mathrm{~h}$ behind UT. The "night group" therefore extends from about 16:00 to 02:00 magnetic time, and the "day group" from 04:00 to 13:00 magnetic time, each occupying periods of 9 or $10 \mathrm{~h}$ and centred about $4 \mathrm{~h}$ before magnetic midnight and noon, respectively. These groups are marked on Fig. 1.

\subsection{Seasonal variation}

Figure 2a shows the event occurrence month by month, in total and for the day and night periods separately. These are averages over all three years, 1990-1992. There is a strong indication of a seasonal variation, in that relatively more days with absorption activity occur during the months of the southern winter than during the summer. The effect is most marked in the night period. There are substantial variations from year to year, no doubt in part statistical but possibly also related to variations in the general levels of geophysical activity.

\subsection{Variations with $A_{p}$}

According to previous studies the general level of auroral absorption varies with the magnetic activity as measured by the standard magnetic indices. The event magnitude depends on $K_{p}-\log$ (absorption) $\propto K_{p}-$ (Hargreaves, 1966). Also the incidence of events (exceeding some threshold magnitude) in monthly periods is essentially linear with $A_{p}(\mathrm{~m})$, this latter being the monthly mean of the daily magnetic index $A_{p}$ (Hargreaves et al., 1987).

Figure 3 illustrates the percentage incidence of days having at least one absorption event, according to the season and month. The plot has been smoothed, and it clearly shows that both magnetic activity and month are major factors.

The incidence of absorption at South Pole is shown in Fig. 4 as a function of $A_{p}$, where the results are given for the four season/time-of-day groups as well as for the total. The day and night periods are, respectively, 08:00-17:00 and 20:00-06:00 UT (Fig. 1), and the winter and summer seasons are May-September and November-March (Fig. 2a).

Panel (b) includes all days having good data, and shows that if other factors are disregarded the probability of there being at least one event in the day increases linearly with $A_{p}$ overall. Given the linearity between event occurrence and $A_{p}$, some correction for the variation of magnetic activity may be applied to the observed monthly incidence. Thus, Fig. $2 \mathrm{~b}$ shows the ratio of occurrence to $A_{p}(\mathrm{~m})$, where $A_{p}(\mathrm{~m})$ is the monthly mean of the $A_{p}$ values for the days inspected. The patterns are not altered significantly by this correction, which confirms that the essential seasonal variation of occurrence is not an artifact due to activity variations from month to month. (The month of December is anomalous for the daytime period, however.)

Panels $4 \mathrm{c}$ to $\mathrm{f}$ also show significant daily and seasonal variations. For $A_{p}$ values up to 25 , the ratio between the percentage probability of an event occurring and $A_{p}$ is 1.1 for winter day, 2.4 for winter night, 0.5 for summer day and 0.4 for summer night. In this respect summer night and day are about the same, but the probability for winter day is about twice as much, and that for winter night is more than twice as much again. Overall, the winter has significantly more absorption activity than the summer at the same level of $A_{p}$. It 

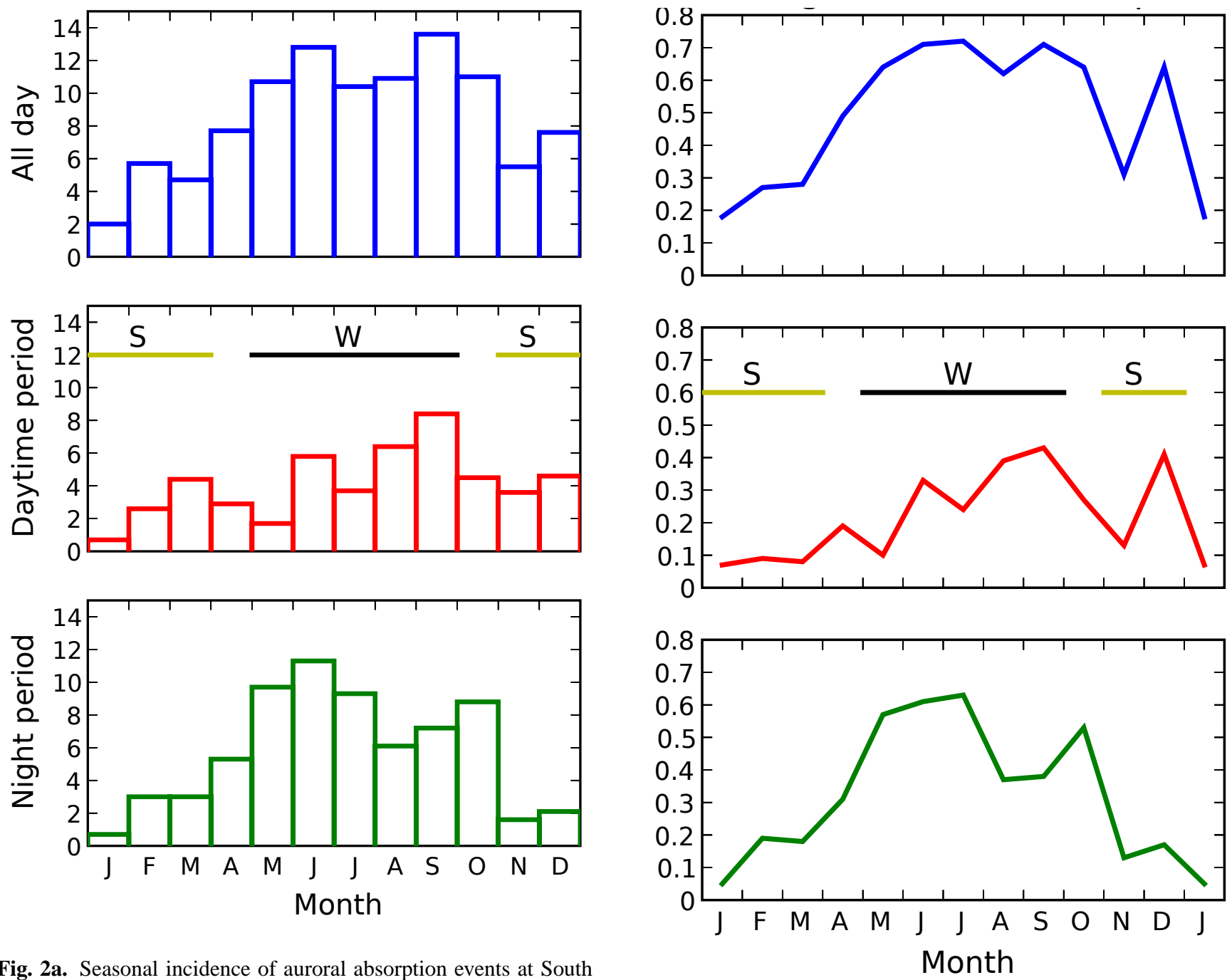

Fig. 2a. Seasonal incidence of auroral absorption events at South Pole over the whole day and within the day and night periods defined in Fig. 1. The plot shows the number of days per year having at least one absorption event exceeding the threshold in a given month. The data have been corrected to a uniform "30-day month". Summer and winter periods are marked.

should be kept in mind that there are fewer data points at the higher disturbance levels, and hence greater statistical variation.

Although there are relatively few days with very high disturbance, the probability of at least one event occurring during the whole day seems to approach unity if all seasons and times of day are included together. Specifically, if $A_{p}>60$ the probability of there being at least one event in the day is 0.78 , and for $A_{p}>70$ it is 0.93 . Our sample has 23 and 14 days in these categories respectively. For comparison, a similar analysis of event incidence at the Abisko station ( $\mathrm{L}=5.6$ ), which is much closer to the maximum of the absorption zone, showed that $A_{p}$ needed to exceed only about 15 for the daily incidence there to approach unity (Hunsucker and Hargreaves, 2003). In that case the threshold was $1 \mathrm{~dB}$ at $30 \mathrm{HMz}$.

Fig. 2b. Seasonal variation of the ratio "event incidence/ $A_{p}(\mathrm{~m})$ ", where $A_{p}(\mathrm{~m})$ is the monthly mean of $A_{p}$.

\subsection{Seasonal variation at high disturbance level}

If the data are now divided according to the time-of-day and seasonal groups an interesting distinction appears. Table 1 shows the event occurrence in the four groups if $A_{p}>60$. There were 9 such days in the summer periods and 14 in the winter, 23 days in all. For three of the groups, the chance of finding an event above the threshold was between 43 and $67 \%$, but no events at all occurred in the summer night periods. In fact, there were no events during the summer night if $A_{p}$ exceeded 35 - note Fig. $4 \mathrm{f}$ - though there were 30 days for which $A_{p} \geq 35$. If the true event probability is 0.5 , the chance of finding none at all in 30 tests is less than 1 in $10^{8}$, which looks highly significant. It appears that there is an anomaly in the incidence of auroral absorption events at South Pole during the summer night when the activity level is very high. 


\section{South Pole events $1990-1992$}
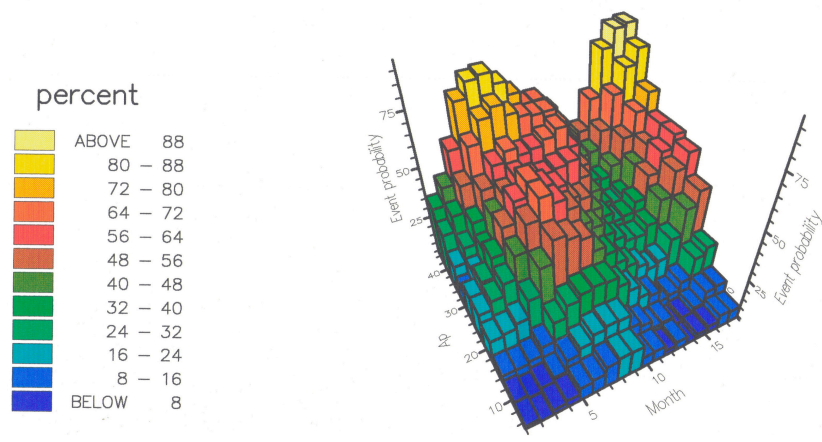

Fig. 3. Probability of at least one absorption event occurring per day at South Pole as functions of month and $A_{p}$. The first six months are repeated after month 12 (December).

(a) Distribution of Ap

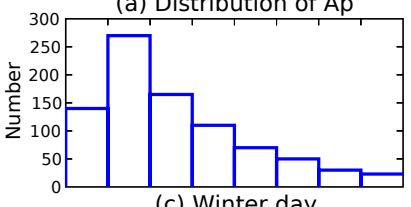

(c) Winter day

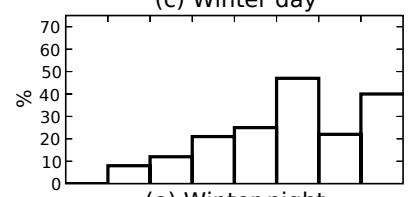

(e) Winter night

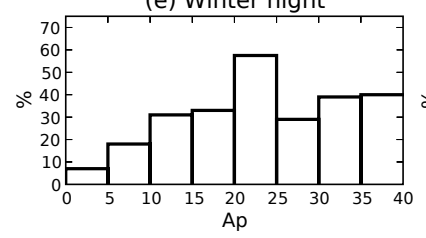

Fig. 4. Variation of event incidence with $A_{p}$ overall and within the defined daily and seasonal divisions. The histograms give the percentage of days having at least one event. The statistical distribution of $A_{p}$ over the three years $1990-1992$ is also shown.

The month by month occurrence of days having at least one event in the night sector, over the three years 1990-1992, is given in Table 2 for days with $A_{p} \geq 35$. From April to July at least $50 \%$ of such days had an event. The percentage declined from August to October, and then from November to March there were no absorption events at all during the night period. Apart from the Januarys, which were exceptionally quiet, these months had a normal quota of geomagnetically active days. We conclude that the absence of auroral absorption when $A_{p}$ is high during the Antarctic summer night is highly significant, and is clearly a seasonal phenomenon rather than a statistical accident.
Table 1. Statistics of event occurrence at high activity, $A_{p}>60$. The daily and seasonal periods are those defined in Figs. 1 and 2.

\begin{tabular}{llll}
\hline Period & $\begin{array}{l}\text { Number of days } \\
\text { when } A_{p}>60\end{array}$ & $\begin{array}{l}\text { Number having } \\
\text { an event }\end{array}$ & $\begin{array}{l}\text { Percentage } \\
\text { occurrence }\end{array}$ \\
\hline Summer day & 9 & 6 & 67 \\
Summer night & 9 & 0 & 0 \\
Winter day & 14 & 7 & 50 \\
Winter night & 14 & 6 & 43 \\
\hline
\end{tabular}

Table 2. Monthly statistics of event occurrence in the night sector when $A_{p}>35$.

\begin{tabular}{llll}
\hline Month & $\begin{array}{l}\text { Number of days } \\
\text { with } A_{p}>35\end{array}$ & $\begin{array}{l}\text { Number with } \\
\text { an event }\end{array}$ & Percentage \\
\hline January & 0 & 0 & - \\
February & 12 & 0 & 0 \\
March & 5 & 0 & 0 \\
April & 6 & 5 & 83 \\
May & 4 & 3 & 75 \\
June & 6 & 3 & 50 \\
July & 6 & 5 & 83 \\
August & 13 & 4 & 31 \\
September & 11 & 2 & 18 \\
October & 7 & 1 & 14 \\
November & 10 & 0 & 0 \\
December & 3 & 0 & 0
\end{tabular}

\section{Occurrence patterns at very high latitude}

Some of the earliest riometer observations in the Antarctic were actually made at latitudes well inside the main absorption zone. Since the absorption is relatively weak and events relatively infrequent, it is more difficult to establish reliable statistics for these latitudes. Nevertheless, some published results from Mirnyy and McMurdo (Table 3) are of interest to the present topic. Figure 5 shows the occurrence of $30 \mathrm{MHz}$ absorption events at Mirnyy and McMurdo.

In the Mirnyy investigation the threshold was set at $0.3 \mathrm{~dB}$ at a radio frequency of $30 \mathrm{MHz}$ (Gillmor and Hargreaves, 1963). Less than a year's full data (from March 1961 to January 1962) were available, and the winter period (Fig. 5a) covers 1 May-15 September, a total of $41 / 2$ months, while summer (Fig. 5b) is represented by the 3 months NovemberJanuary inclusive. These were the first observations of auroral radio-absorption events to be made in the Antarctic, and the authors pointed out that the diurnal pattern of occurrence changed with the season. Figures $5 \mathrm{a}$ and $\mathrm{b}$ clearly indicate a preference for the night period in winter, and for the day period (though the incidence is small) in the summer. 
Table 3. Station parameters.

\begin{tabular}{llll}
\hline Station & $\begin{array}{l}\text { Geographic } \\
\text { coordinates }\end{array}$ & L value & $\begin{array}{l}\text { Magnetic } \\
\text { midnight } \\
\text { (approx) }\end{array}$ \\
\hline South Pole (SPA) & $90^{\circ} \mathrm{S},-$ & 14 & $04: 00 \mathrm{UT}$ \\
Mirnyy (MIR) & $66.6^{\circ} \mathrm{S}, 93.0^{\circ} \mathrm{E}$ & 19.5 & $21: 00 \mathrm{UT}$ \\
McMurdo (MCM) & $77.85^{\circ} \mathrm{S}, 166.7^{\circ} \mathrm{E}$ & 30 & $07: 00 \mathrm{UT}$ \\
\hline
\end{tabular}

(a) Mirnyy winter
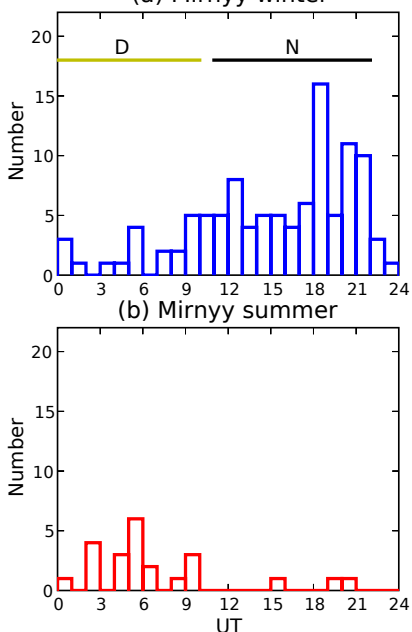

(c) McMurdo winter
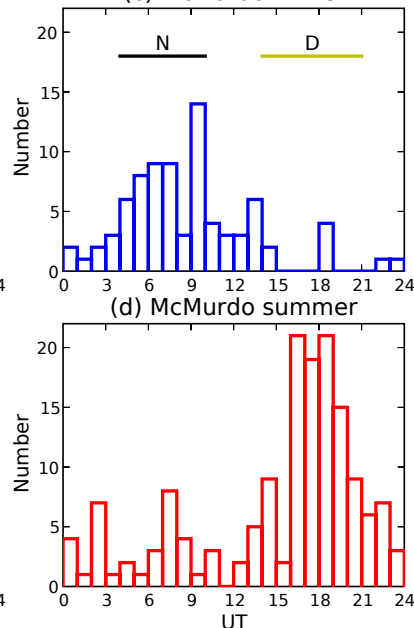

Fig. 5. Diurnal event occurrence at very high latitudes: (a) Mirnyy winter; (b) Mirnyy summer; (c) McMurdo winter; (d) McMurdo summer. The day and night periods of event occurrence were defined by inspection of the plots.

The day and night periods marked on Fig. 5a cover approximately 03:00-13:00 and 14:00-01:00 local magnetic time, respectively.

At McMurdo the absorption activity is even weaker. The observations of Satterblom et al. (1967) covered 5 years from 1962-1967, and the incidence of events exceeding $0.25 \mathrm{~dB}$ (at $30 \mathrm{MHz}$ ) was only 5.6 per month on average. Figures $5 \mathrm{c}$ and d take May to September as winter and November to March as summer, each a period of 5 months duration. The data from all 5 years are included. Again we see a clear preference for night activity in the winter and for day activity in the summer. The day and night periods marked on Fig. $5 \mathrm{c}$ cover approximately 07:00-14:00 and 21:00-03:00 magnetic time. Satterblom et al. remarked that September appeared to be a transitional month between the summer and winter patterns.

In neither of these studies did the analysis take account of $A_{p}$, so we do not know at what level of disturbance the events were seen or the asymmetry began to operate. However, since the effect is present in the total set of data, it pre-

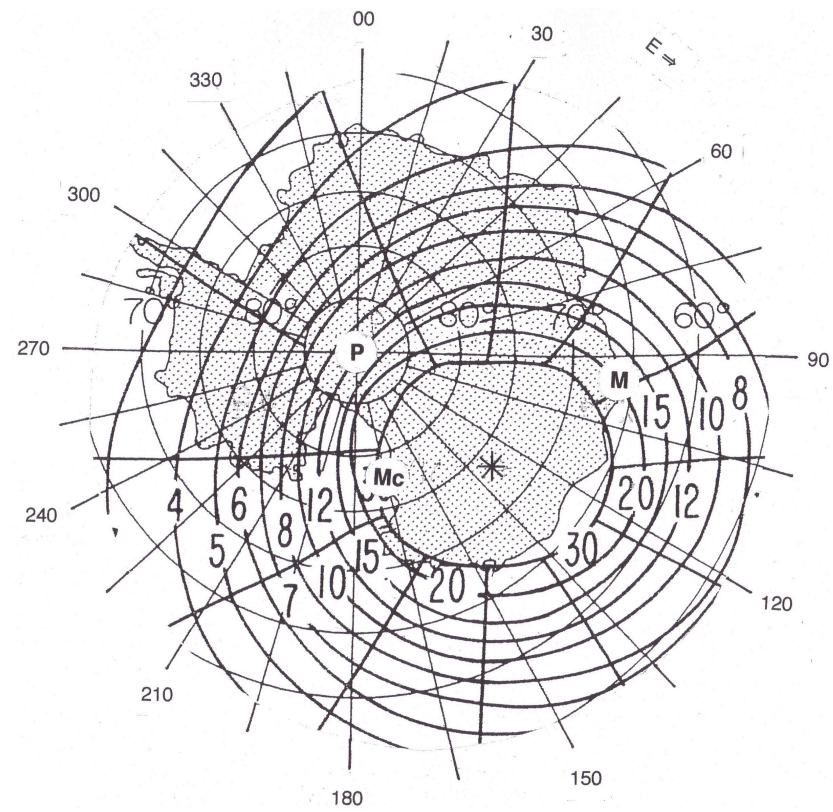

Fig. 6. Map of Antarctic continent with stations South Pole (SPA), Mirnyy (MIR) and McMurdo (MCM), and constant L contours.

sumably operates at virtually all activity levels for which auroral absorption occurs at these very high latitudes.

There is an element of consistency between the results from South Pole, Mirnyy and McMurdo, which may be appreciated from the geography. In Fig. 6 the L-values are superposed on a map of the Antarctic (after Hargreaves, 1967), with the observing sites marked as SPA, MIR, and MCM respectively. At midnight UT the Sun is on the $180^{\circ}$ meridian of geographical longitude, and relative to the map it moves $15^{\circ}$ westward each hour. For each of the stations the magnetic-night period of absorption occurs when the station is on the opposite side of the magnetic pole (*) from the Sun. For Pole and Mirnny the time when the Sun, the magnetic pole, and the station are aligned comes near the end of the night period of event incidence (Figs. 1 and 5). The situation is slightly different for McMurdo, when the alignment falls nearer the middle of the period. During the day periods, stations are on the sunward side of the magnetic pole and similar considerations apply. In the summer season, when the pole is tilted toward the Sun, the night period of activity virtually vanishes at the highest latitudes, while at South Pole it vanishes at high activity. In the winter, when the pole is tilted away from the Sun, it is the the day period of activity which vanishes at the highest latitudes (though not at South Pole).

\section{A basic explanation}

It is suggested that the lack of absorption during summer nights at South Pole is a consequence of the changing geometry of the magnetotail resulting from the seasonal change 
Effect of a tail field hinged at $5 \mathrm{Re}$

(with tapering) in southern summer.
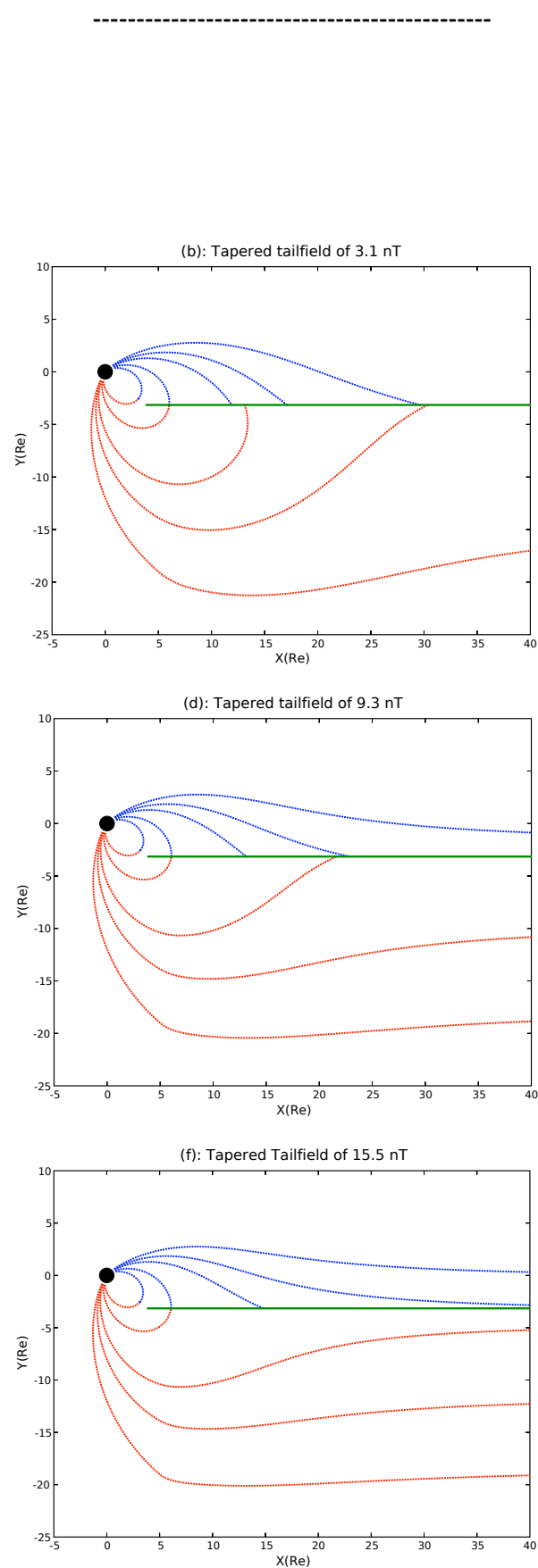

(a): Tailfield of $0 \mathrm{nT}$

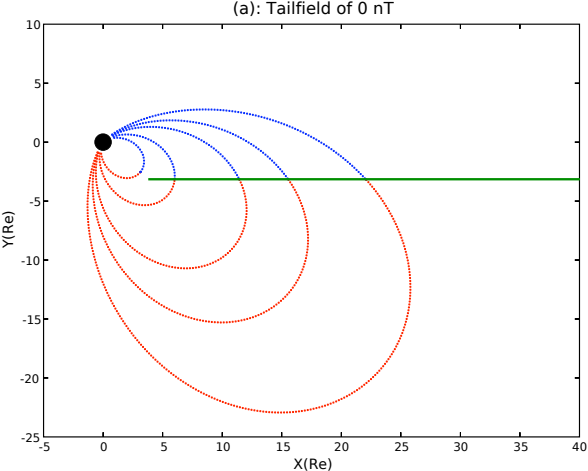

(c): Tapered tailfield of $6.2 \mathrm{nT}$

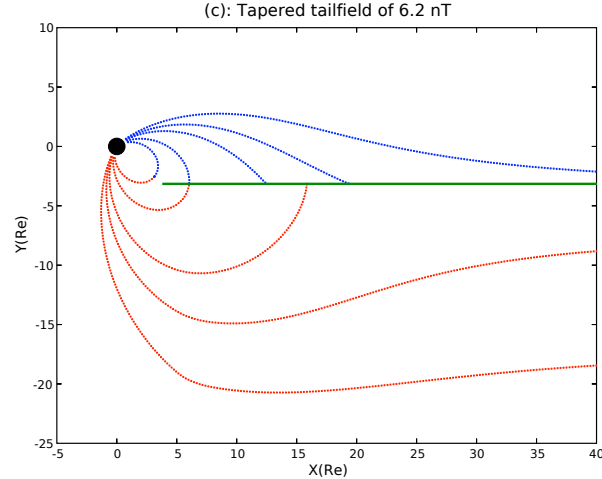

(e): Tapered tailfield of $12.4 \mathrm{nT}$

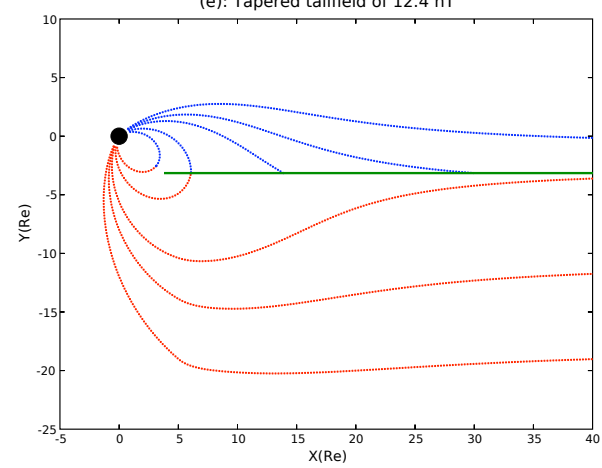

(g): Tapered tailfield of $18.6 \mathrm{nT}$

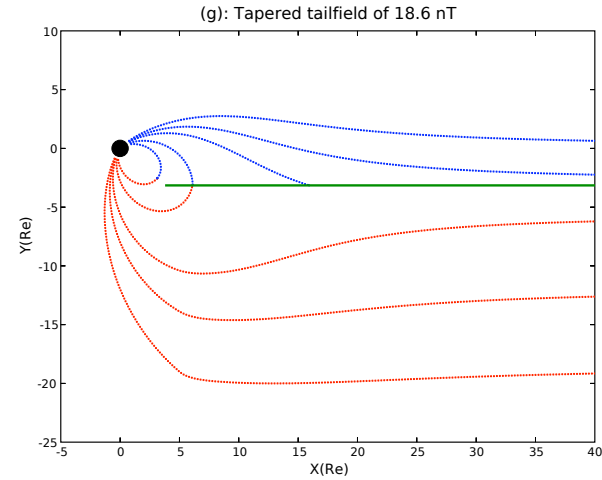

Fig. 7. Field-line tracings on the night side for $\mathrm{L}=4,7,14,20$ and 30, showing the effect of increasing tail field. The neutral sheet has been "hinged" to the dipole field at $5 R_{E}$ (see text). In the Antarctic summer the angle between the geomagnetic equator and the ecliptic plane is $39^{\circ}$. The third line out represents the L-value of South Pole. 
Effect of a tail field hinged at $5 \mathrm{Re}$

(with tapering) in southern winter.
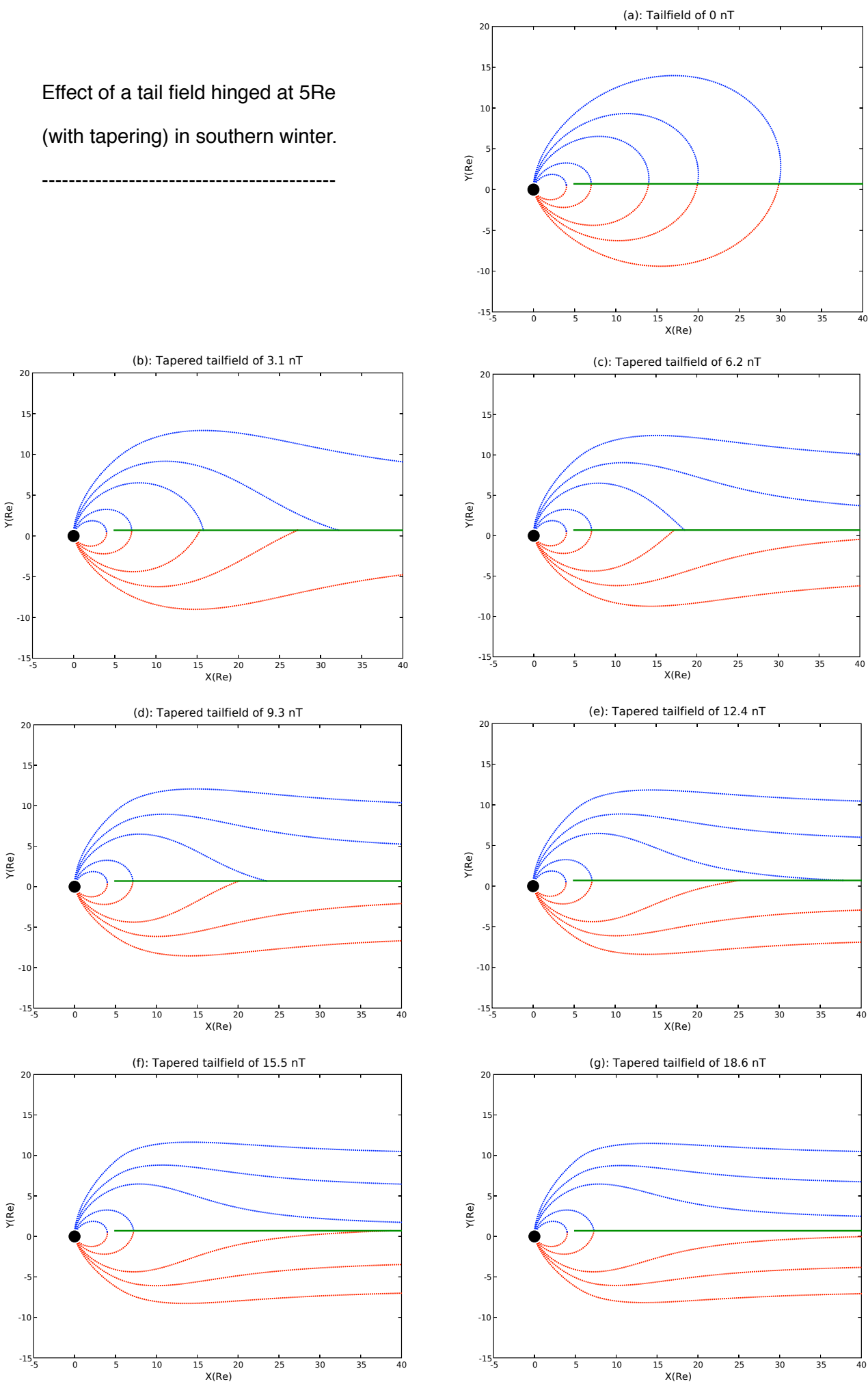

Fig. 8. Night-side field tracings for the southern winter and northern summer, the angle between geomagnetic equator and ecliptic plane being $8^{\circ}$. 


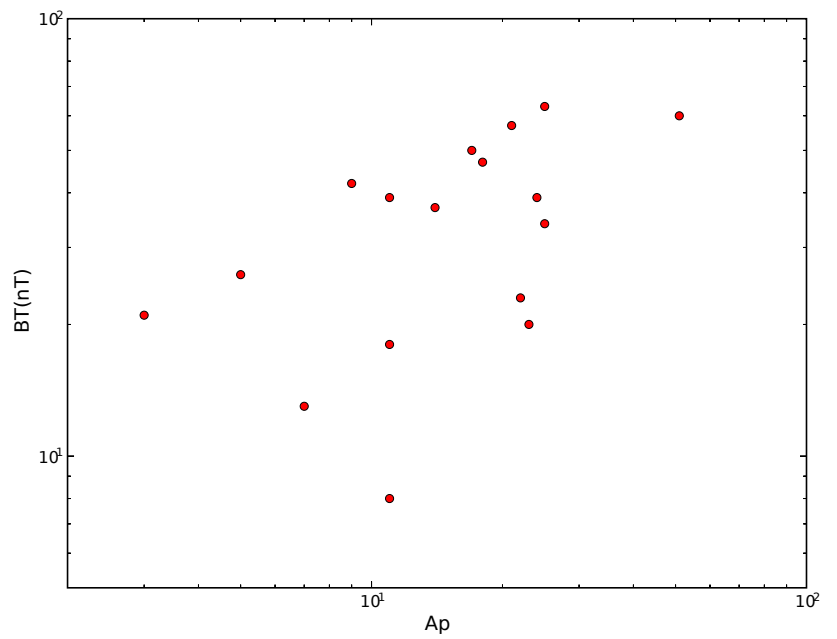

Fig. 9. Relation between tail field observed by GEOTAIL just before the onset of substorms and the index $A_{p}$ for that day (Courtesy K. Shiokawa).

in the orientation of the magnetosphere with respect to the solar wind. The point is illustrated in Fig. 7 by means of simplified models of the geomagnetic field, comprising just a dipole field plus a tail field. The tail field is assumed to commence at $5 R_{E}$ and to run parallel to the ecliptic plane (i.e. in the Sun-Earth direction). This "hinging" of the tail goes back to the earliest attempts to model the effect of the tail on the shape of the magnetosphere (e.g. Speiser and Ness, 1967) and most workers have made the connection at 8 or $10 R_{E}$. The closer distance of $5 R_{E}$ has been used here because observations indicate that the substorm in auroral absorption in the night sector begins at about $\mathrm{L}=5$ (Hargreaves et al., 1975). However, the value is tapered from zero at $5 R_{E}$ to the full value at $8 R_{E}$. The tail fields have been selected as $3.1,6.2,9.3,12.4,15.5$ and $18.6 \mathrm{nT}$, these being convenient fractions $\left(1.10^{-4}\right.$ to $\left.6.10^{-4}\right)$ of the Earth's dipole field at the equator.

At magnetic midnight in midsummer, the geomagnetic equator in the anti-solar direction lies at an angle some $39^{\circ}$ below the ecliptic plane. If the tail field $\left(\mathrm{B}_{T}\right)$ is zero, the field-lines from magnetically conjugate points in Northern and Southern Hemispheres join as expected and conjugacy is preserved. The addition of a tail field moves the point where a selected field-line meets the neutral sheet further out, the extension being greater in the Southern Hemisphere. Table 4 gives the intersection not with the neutral sheet but with a line three Earth-radii from it, representing the thickness of a typical plasma sheet. In the southern summer (northern winter) the line from the south meets the sheet several earth-radii further down the tail than the northern line, and the difference increases with the magnitude of the tail field. When the field reaches about $20 \mathrm{nT}$ (in this model!) the southern line is effectively open, whereas the northern line still connects into
Table 4. Intersection distances (in $R_{E}$ ) of the $\mathrm{L}=14$ fieldlines with the edge of a plasma sheet assumed to be of $3 R_{E}$ half-width, illustrating the possible effects of increasing tail field and changing season.

\begin{tabular}{lllll}
\hline B (nT) & $\begin{array}{l}\text { Winter, } \\
\text { North }\end{array}$ & $\begin{array}{l}\text { Summer, } \\
\text { South }\end{array}$ & $\begin{array}{l}\text { Summer, } \\
\text { North }\end{array}$ & $\begin{array}{l}\text { Winter, } \\
\text { South }\end{array}$ \\
\hline 0 & n/a & n/a & n/a & n/a \\
3.1 & 8.8 & 13.2 & 14.2 & 12.9 \\
6.2 & 8.9 & 14.8 & 15.0 & 13.5 \\
9.3 & 9.0 & 16.9 & 16.2 & 14.0 \\
12.4 & 9.1 & 19.9 & 17.5 & 14.7 \\
15.5 & 9.2 & 25.7 & 19.4 & 15.4 \\
18.6 & 9.2 & $>40$ & 21.7 & 16.2 \\
31 & 9.5 & $>40$ & $>40$ & 21.8 \\
62 & 10.8 & $>40$ & $>40$ & $>40$ \\
\hline
\end{tabular}

the plasma sheet even for a large field. (For the table, the computations were extended to 31 and $62 \mathrm{nT}$, equivalent to fractions $1.10^{-3}$ and $2.10^{-3}$.)

When it is midwinter in the south, the geomagnetic equator is above the ecliptic but only by $8^{\circ}$. The effect then works in the opposite direction but to a lesser extent (Fig. 8). The separations between northern and southern intersections with the plasma sheet are smaller, and the tail field has to be considerably larger before the southern (winter) line opens. For the lines $\mathrm{L}=20$ and 30 the effects are greater.

In this study the activity level has been quantified by the magnetic disturbance index $A_{p}$, and the relation between $B_{T}$ and $A_{p}$ is not well defined though observations have indicated a tendency for them to increase together. Early observations revealed the tail field to be larger on average for higher values of the $K_{p}$ index. Values such as $8-25 \mathrm{nT}$ were quoted for conditions when $K_{p} \leq 2-$, and of 10-30nT at greater $K_{p}$, with $40 \mathrm{nT}$ seen only during the largest disturbances (Behannon and Ness, 1966). A doubling of tail field (to $30 \mathrm{nT}$ ) was reported at the sudden commencement (SC) of a storm in which $K_{p}$ rose to 6 (Ness and Williams, 1966). In the present analysis an $A_{p}$ value of 35 appears to be significant. This would be roughly equivalent to $K_{p} \sim 4$, at which $B_{T}$ would (typically) be considerably enhanced.

More recently, Shiokawa et al. (2005) used GEOTAIL data from the years 1995-2000 to investigate fluctuations of magnetic field at 8 to 11 Earth-radii during substorms. Figure 9 shows the values of $B_{T}$ just before the substorm against the value of $A_{p}$ on that day. (In some cases the observed value of $B_{T}$ may have been reduced by the pressure due to the plasma within the tail.) The correlation between these quantities is again poor. There is a large range of $B_{T}$ at any selected value of $A_{p}$, but the tendency for it to increase with $A_{p}$ is apparent: there is a lack of large values of $B_{T}$ if $A_{p}$ is small , and a lack of small values of $B_{T}$ if $A_{p}$ is large. On this evidence, also, the tail field is likely to be enhanced if $A_{p}$ exceeds 35 . 
The simple calculations in this section should not be mistaken for an accurate model of the magnetotail. They are intended only to illustrate a principle, and for a first-order comparison with the observations. The agreement seems as good as can be expected.

\section{Summary and discussion}

The concept that field-lines originating at high latitude are swept back into the tail goes back many years, and it was early recognised that the details would be largely determined by the intensity of the tail field. Model computations by Barish and Roederer (1969) predicted that at L 7 (Byrd station) there would be conjugate displacements for the smaller values of tail field but that the field lines would be open if the tail field was large. Evidence for the opening of the fieldlines has not, however, been observed in riometer data from $\mathrm{L}=7$. The higher latitude of South Pole would be expected to be more susceptible to the effect, and the present analysis suggests that, being observed at high disturbance level only, and in summer but not in winter, it is just beginning to show up at that latitude. $\mathrm{L} \approx 14$ is a transitional latitude in this sense.

At lower disturbance levels, when the fieldlines go back to the central tail, the event incidence is observed to be approximately proportional to the $A_{p}$ index, and there are at least twice as many events (exceeding a given magnitude) in the winter as in the summer. The preference for winter is consistent with the conjugate-point observations of Hargreaves and Chivers (1965) which showed the absorption to be generally stronger in the winter hemisphere of the $\mathrm{L}=14$ conjugate pair. The displacement of plasma-sheet connection points (Table 4) may well be a factor.

The observations at L-values of 20 and more show that an even stronger seasonal effect operates at these very high magnetic latitudes. There is good consistency between the results from Mirnyy and McMurdo, in that the night group of events in each case weakens or disappears in the local summer, and the day group vanishes in the local winter. At these latitudes the whole data set is affected, not just the periods with highest magnetic activity.

A simple model, produced by adding a tail field to the Earth's dipole, can explain the night effect in terms of the changing configuration of the magnetotail when the southern pole is tilted towards the Sun. The use of absorption statistics from high-latitude sites in conjunction with field modelling appears to offer further scope for studying the connection between high-latitude ground stations and active regions of the magnetotail.

Recent auroral studies have investigated the influence of the interplanetary magnetic field (IMF) on the motion (Ostgaard et al., 2003) and conjugacy (Ostgaard et al., 2004; Stubbs et al., 2005) of auroral phenomena. It would be of interest to include IMF behaviour in further studies of absorption at very high latitudes.

Acknowledgements. I am grateful to T. J. Rosenberg and D. L. Detrick for making available the riometer data from South Pole, and to K. Shiokawa for sight of his data on the tail field and for helpful comments. The study was begun during a visit to the University of Maryland several eons ago.

Topical Editor M. Pinnock thanks two referees for their help in evaluating this paper.

\section{References}

Barish, F. D. and Roederer, J. G.: Influence of a magnetospheric cavity model field on geomagnetic conjugacy of high latitude stations, University of Denver report, July 1969.

Behannon, K. W. and Ness, N. F.: Magnetic storms in the earth's magnetic tail, J. Geophys. Res., 71, 2327-2351, 1966.

Gillmor, C. S. and Hargreaves, J. K.: The occurrence of shortduration cosmic noise absorption events inside the southern auroral zone, J. Atmos. Terr. Phys., 25, 311-317, 1963.

Hargreaves, J. K., Chivers, H. J. A., and Petlock, J. D.: A study of auroral absorption events at the South Pole. 1. Characteristics of the events, J. Geophys. Res., 69, 5001-5007, 1964.

Hargreaves, J. K. and Chivers, H. J. A.: A study of auroral absorption events at the South Pole. 2. Conjugate properties, J. Geophys. Res., 70, 1093-1102, 1965.

Hargreaves, J. K.: On the variation of auroral radio absorption with geomagnetic activity, Planet. Space Sci., 14, 991-1006, 1966.

Hargreaves, J. K. and Cowley, F. C.: Studies of auroral radio absorption events at three magnetic latitudes. 1. Occurrence and statistical properties of the events, Planet. Space Sci., 15, 15711583, 1967a.

Hargreaves, J. K. and Cowley, F. C.: Studies of auroral radio absorption events at three magnetic latitudes. 2. Differences between conjugate regions, Planet. Space Sci., 15, 1585-1597, 1967b.

Hargreaves, J. K.: A simple conjugate-point map. Technical Memorandum IERTM-ITSA 101, Institute of Telecommunication Sciences and Aeronomy, Boulder, Colorado, 1967.

Hargreaves, J. K.: Auroral absorption of HF radio waves in the ionosphere: a review of results from the first decade of riometry, Proc. IEEE, 57, 1348-1373, 1969a.

Hargreaves, J. K.: Conjugate and closely-spaced observations of auroral radio absorption. I. Seasonal and diurnal behaviour, Planet. Space Sci., 17, 1459-1484, 1969b.

Hargreaves, J. K., Chivers, H. J. A., and Axford, W. I.: The development of the substorm in auroral radio absorption, Planet. Space Sci. 23, 905-911, 1975.

Hargreaves, J. K., Feeney, M. T., Ranta, H., and Ranta, A.: On the prediction of auroral radio absorption on the equatorward side of the absorption zone, J. Atmos. Terr. Phys., 49, 259-272, 1987.

Hunsucker, R. D. and Hargreaves, J. K.: The high-latitude ionosphere and its effects on radio propagation, Cambridge University Press, Cambridge, p.366, 2003.

Ness, N. F. and Williams, D. J.: Correlated magnetic field and radiation belt observations, J. Geophys. Res., 71, 322-325, 1966.

Ostgaard, N., Detrick, D. L., Rosenberg, T. J., Vondrak, R. R., Frey, H. U., Mende, S. B., Haland, S. E., and Stadsnes, J.: Highlatitude dayside energetic precipitation and IMF $B_{Z}$ rotations, 
J. Geophys. Res., 108(A4), 8013, doi:10.1029/2002JA009350, 2003.

Ostgaard, N., Mende, S. B., Frey, H. U., and Immel, T. J.: Interplanetary magnetic field control of the location of substorm onset and auroral features in the conjugate hemispheres, J. Geophys. Res., 109(A7), A07204, doi:10.1029/2003JA010370, 2004.

Satterblom, P. R., Masley, A. J., and Santina, R. E.: The time distribution of small absorption events at high conjugate locations. Proceedings of Conjugate Point Symposium, Boulder, Colorado, USA, June 1967, ESSA Technical Memorandum IERTM-ITSA 72, Vol. I, pp II-16-1-13, July 1967.
Shiokawa, K., Shinohara, I., Mukai, T., Hayakawa, H., and Cheng, C. Z.: Magnetic field fluctuations during substorm-associated dipolarizations in the nightside plasma sheet around $\mathrm{X}=-10 R_{E}$, J. Geophys. Res., A05212, 110, 2005.

Speiser, T. W. and Ness, N. F.: The neutral sheet in the geomagnetic tail: its motion, equivalent currents and field-line convection through it, J. Geophys. Res., 72, 131-141, 1967.

Stubbs, T. J., Vondrak, R. R., Ostgaard, N., Sigwarth, J. B., and Frank, L. A.: Simultaneous observations of the auroral ovals in both hemispheres under varying conditions, Geophys. Res. Lett., 32(3), L03103, doi:10.1029/2004GL021199, 2005. 